\title{
Spatial distribution of leprosy in areas of risk in Vitória, State of Espírito Santo, Brazil, 2005 to 2009
}

\author{
Poliane Barbosa Sampaio ${ }^{[1]}$, Elizabeth Santos Madeira ${ }^{[2]}$, Lúcia Diniz ${ }^{[3]}$, \\ Ethel Leonor Noia ${ }^{[1]}$ and Eliana Zandonade ${ }^{[1]}$
}

[1]. Programa de Pós Graduação em Saúde Coletiva, Universidade Federal do Espírito Santo, Vitória, ES. [2]. Curso de Medicina, Faculdade Univix, Vitória, ES. [3]. Departamento de Clínica Médica, Universidade Federal do Espírito Santo, Vitória, ES.

\begin{abstract}
Introduction: Leprosy remains a relevant public health issue in Brazil. The objective of this study was to analyze the spatial distribution of new cases of leprosy and to detect areas with higher risks of disease in the City of Vitória. Methods: The study was ecologically based on the spatial distribution of leprosy in the City of Vitória, State of Espírito Santo between 2005 and 2009. The data sources used came from the available records of the State Health Secretary of Espírito Santo. A global and local empirical Bayesian method was used in the spatial analysis to produce a leprosy risk estimation, and the fluctuation effect was smoothed from the detection coefficients. Results: The study used thematic maps to illustrate that leprosy is distributed heterogeneously between the neighborhoods and that it is possible to identify areas with high risk of disease. The Pearson correlation coefficient of $0.926(p=0.001)$ for the Local Method indicated highly correlated coefficients. The Moran index was calculated to evaluate correlations between the incidences of adjoining districts. Conclusions: We identified the spatial contexts in which there were the highest incidence rates of leprosy in Vitória during the studied period. The results contribute to the knowledge of the spatial distribution of leprosy in the City of Vitória, which can help establish more cost-effective control strategies because they indicate specific regions and priority planning activities that can interfere with the transmission chain.
\end{abstract}

Keywords: Leprosy. Epidemiology. Spatial distribution.

\section{INTRODUCTION}

Leprosy is an infectious disease caused by the bacillus Mycobacterium leprae, which can affect both sexes and all ages $^{1}$. According to the World Health Organization (WHO), 228,474 new cases of the disease were detected worldwide in 2010 , constituting a significant public health problem. Brazil is included among the seven countries with the highest numbers of leprosy cases, with 34,894 new cases of the disease in $2010^{2,3}$.

The State of Espirito Santo, as in the rest of Brazil, showed a declining trend of leprosy in recent years, but the level of endemicity is higher than the average in the Southeast Region of the country. In 2010, the prevalence rate of leprosy in the State was 2.82 cases per 10,000 inhabitants, placing Espírito Santo as the state with the highest prevalence of the disease in the Southeast Region ${ }^{4,5}$.

The City of Vitória, the capital of Espírito Santo, has been described as an area of very high endemic disease (22.80 cases

Address to: Dra. Poliana Barbosa Sampaio. Rua Maria Eleonora Pereira 605/302 B115 Ed: Fênix II, Jardim da Penha, 2906-0180 Vitória, ES, Brasil.

Phone: 5527 8153-3565

e-mail: polianebsampaio@hotmail.com

Received: 11 December 2012

Accepted: 22 May 2013 per 100,000 people in 2009) according to Ministry parameters ${ }^{6}$. The detection of new leprosy cases has significantly increased, qualifying the State for the priority disease control program.

In the area of health research, the spatial distribution approach is gaining prominence due to the use of maps for representing spatial events, which is useful to prevent artificial fragmentation of the studied region by applying political and administrative criteria. Furthermore, spatial statistical techniques have improved our understanding of spatial dependents and the occurrence of diseases ${ }^{7}$.

To observe possible areas to be prioritized in planning actions for the prevention and control of leprosy, an important tool, the Geographic Information System (GIS), is used ${ }^{8}$.

Thus, the aim of this study was to analyze the spatial distribution of new cases of leprosy, thereby detecting areas of increased risk of disease in the City of Vitória (Espírito Santo, Brazil).

\section{METHODS}

Between the years of 2005 and 2009, an ecological study of secondary data was performed in Vitória. The city is the capital of the State of Espírito Santo and is divided into an island section, the birthplace of the city and a continental section of recent growth. Its population is 320,156 inhabitants in an area of 104.3 square kilometers, and it is divided into 78 districts, which were the units of analysis of the study? 
The capital, Vitória, is sub-divided into six health regions: Region I - Continental (of recent occupation, but the most populous); Region II - Maruipe; Region III - Downtown; Region IV - Santo Antonio; Region V - São Pedro; and Region VI - The Sao João Fort ${ }^{4,10}$. The city has a small land area with notable socioeconomic, demographic and historical differences among regions.

The data from new leprosy patients living in the City of Vitória recorded in the Information System for Notifiable Diseases (SINAN) between 2005 and 2009 were used. Population data were obtained from the Brazilian Institute of Geography and Statistics (IBGE), and the cartographic base was provided by Geo-Foundations, through the Treasury Department of the City of Vitória.

The calculation of incidence rates was performed by dividing the sum of new leprosy cases according to neighborhood by the sum of the population between the years 2005 to 2009; the result was then multiplied by 100,000 to adopt the Health Surveillance System/Ministry of Health SVS/MS ${ }^{11}$. Both the crude incidence rate and the data tabulation of SINAN were performed in a Microsoft Excel spreadsheet.

The Local Empiric Bayesian model (LEBayes) was used for the spatial analysis of data, thus mitigating the effects of random fluctuation in detection rates resulting from the calculation of rates for small areas. This procedure uses the estimation of constructed spatial averages, with the criterion of neighborhood adjacency condition between neighborhoods as geographical units ${ }^{12}$.

The Pearson correlation coefficient and scatter plots were used to evaluate the correlation between results of detection of coefficients, the estimated gross average and the Bayesian averages calculated by the Bayesian method.

The behavior of the spatial distribution of leprosy when the neighborhoods of Vitória City, State of Espírito Santo are considered can express the existence of dependence between the incidence rates of new cases. To complement studies of spatial autocorrelation between rates, the local Moran index (LISA) was calculated, and when the significance values were less than 0.05 , regions with spatial structures of leprosy onset were indicated ${ }^{13}$.

The WHO has defined parameters for the detection rates of leprosy to categorize the levels of endemicity of the disease: areas are hyperendemic when their coefficient is greater than 40.00 cases per 100,000 inhabitants, very high with 20.00 to 39.99 cases per 100,000 inhabitants, high with 10.00 to 19.99 cases per 100,000 inhabitants, average with 2.00 to 9.99 cases per 100,000 inhabitants and low when the endemicity of the disease is lower than 2.00 cases per 100,000 inhabitants ${ }^{6,14}$.

Statistical analyses of risk population and its neighborhood were performed using Terra View 4.0.0 free software (http:// www.dpi.inpe.br/terraview/index.php).

\section{Ethical considerations}

Regarding ethical aspects, it is important to emphasize that the entire research process was conducted according to
Resolution $\mathrm{N}^{\circ}$. 196/96 of the National Health Council (CNS), and the research project was approved by the Ethics and Research Board of the Federal University of Espírito Santo, under registration 165/11.

\section{RESULTS}

Table 1 shows the detection coefficients in the city according to years of notification. Notably, between 2005 and 2009, the detection coefficient for leprosy in Vitória decreased, although it was still classified as very high ${ }^{6}$.

TABLE 1 - New cases of leprosy per year and the detection coefficients in Vitória, State of Espírito Santo, Brazil, 2005-2009.

\begin{tabular}{lccc}
\hline Year & Population & New cases & $\begin{array}{c}\text { General coefficient } \\
\text { of detection }\end{array}$ \\
\hline 2005 & 313,309 & 94 & 29.99 \\
2006 & 317,083 & 63 & 19.86 \\
2007 & 320,822 & 72 & 22.93 \\
2008 & 317,817 & 77 & 24.23 \\
2009 & 320,153 & 73 & 22.80 \\
\hline
\end{tabular}

Source: SINAN: Information System for Notifiable Diseases.

Using the Ministry of Health parameters for the classification level of endemicity, the distribution of the mean detection rates of leprosy was analyzed by neighborhood. The results indicated that $18(22.2 \%)$ were classified as hyperendemic and $20(24.7 \%)$ as very high endemic; $9(11.1 \%)$ were of average endemicity, and other districts presented low endemicity.

Figure 1 shows the spatial distribution of the raw detection coefficient (A) adjusted by the Local Method (B) and the Global Method (C) for leprosy. The thematic map indicated areas with greater disease severity that exhibited significant growth in detection rates, which ranged from low to hyperendemic.

With the Local Method, it is possible to observe that by smoothing the neighborhood of each district, a concentration of cases that arose increased from low to medium for neighborhoods with high detection rates, thus highlighting foci with greater case occurrences. The Global Method highlighted neighborhoods that went from areas of low concentration to areas with medium and high detection rates. It is also worth noting that some neighborhoods went from hyperendemic to areas with high detection rates. (Figure 1)

Figure 2A and $\mathbf{B}$ show the scatter plots for the crude coefficients and the adjusted coefficients by the Local and Global Ebest methods, respectively. The Pearson correlation coefficients were $0.926(p=0.001)$ for the Local method and $0.981(\mathrm{p}=0.001)$ for the Global method, which indicated that the coefficients are highly correlated. The Local method presents greater data dispersion compared to the Global method. 


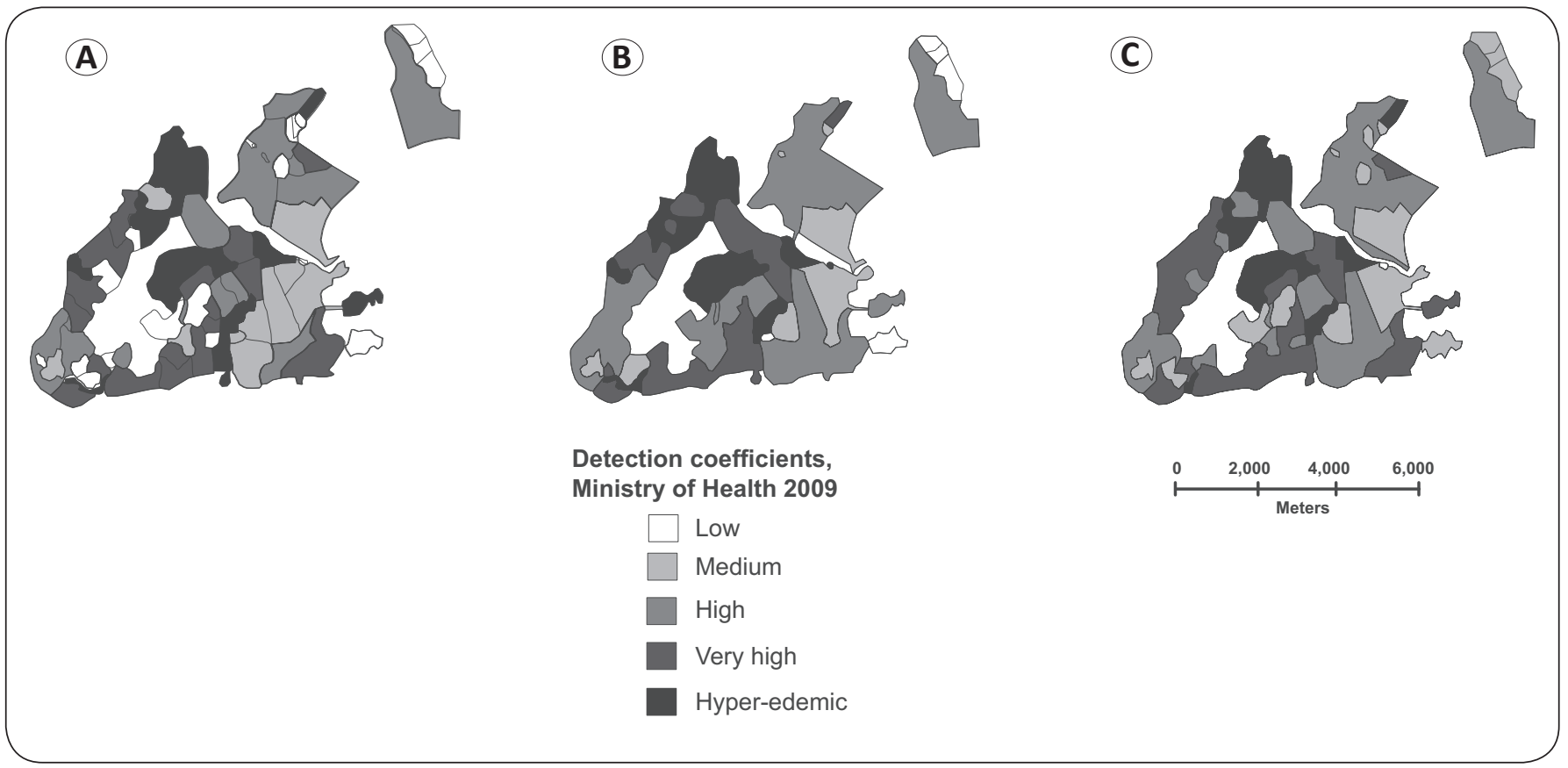

FIGURE 1 - Map of the average coefficients of detection of leprosy cases in Vitória, State of Espírito Santo, Brazil, 2005-2009. A: raw coefficient; B: adjusted coefficient using the Local Ebest method; C: adjusted coefficient using the Global Ebest method.

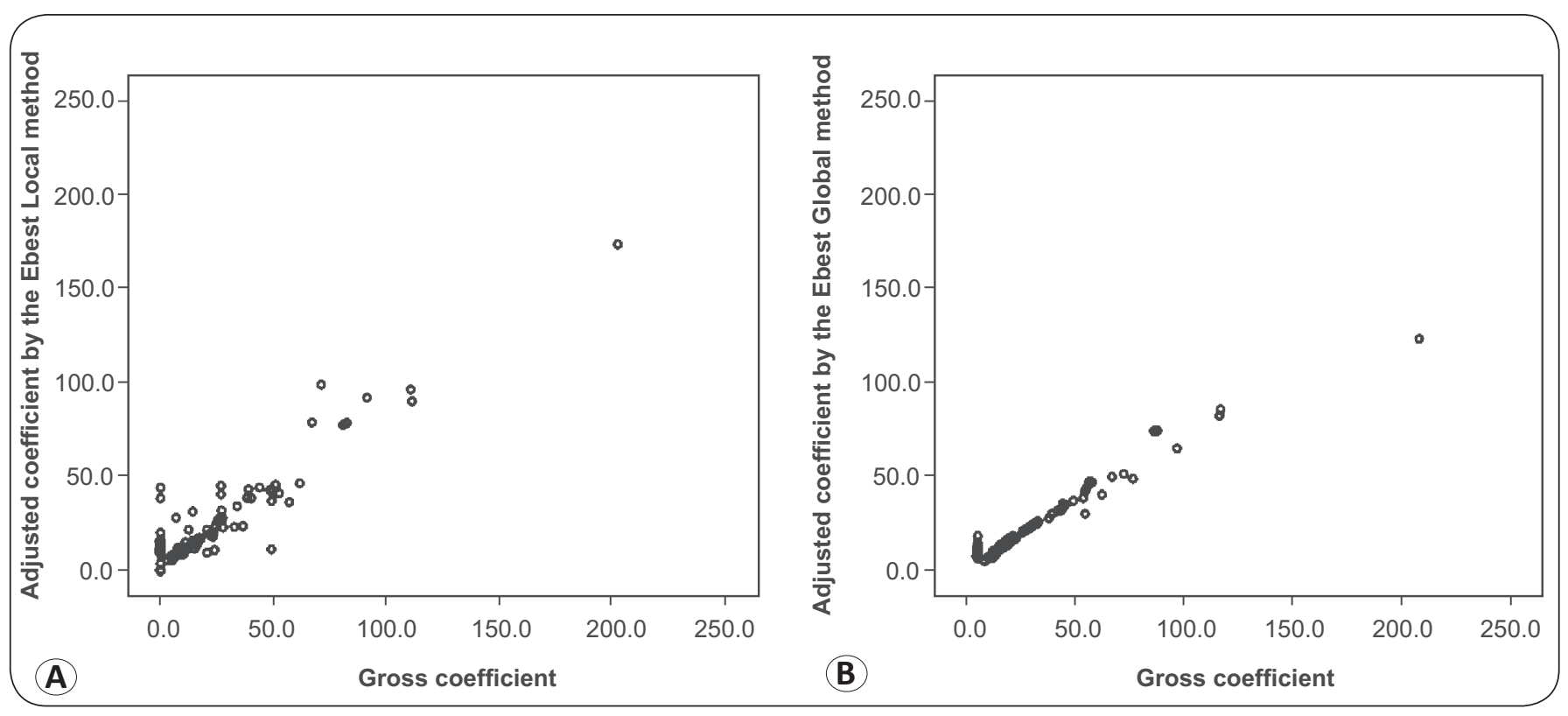

FIGURE 2 - Scatter diagram of the average coefficients of detection of leprosy cases in Vitória, State of Espírito Santo, Brazil, 2005-2009, between gross coefficients. A: Adjusted coefficient by the Local Ebest method; B: Adjusted coefficient by the Global Ebest method.

Table 2 presents the detection coefficient parameters (hyperendemic and very high, high, medium and low endemicity), comparing the gross value with values estimated by the Bayesian Local and Global methods for the 78 districts studied.

The results for the Local method showed that 45 districts maintained their original classifications, 22 neighborhoods changed classifications to higher endemicity, and 11 districts moved to a lower endemicity.
The results for the Global method showed that 54 districts maintained their original classifications, 20 districts changed their classifications to higher endemicity, and four moved to lower endemicity. These results suggest that neighborhoods that showed changes in classification had a tendency to increase the detection rate.

Using the Bayesian method, it was possible to observe that the region located in San Pedro Bay, northwest of Vitória, consists of 10 districts and shows a greater spatial concentration 
TABLE 2 - Parameters of detection rates compared with the gross values adjusted by Bayesian Local and Global Methods.

\begin{tabular}{|c|c|c|c|c|c|c|c|c|c|c|}
\hline Gross coefficient & \multicolumn{5}{|c|}{ Local Ebest } & \multicolumn{5}{|c|}{ Global Ebest } \\
\hline \multicolumn{11}{|l|}{ Low } \\
\hline $\mathrm{n}$ & 3 & 3 & 8 & 1 & 1 & 0 & 8 & 8 & 0 & 0 \\
\hline$\%$ & 19.0 & 19.0 & 50.0 & 6.0 & 6.0 & 0.0 & 50.0 & 50.0 & 0.0 & 0.0 \\
\hline $\mathrm{n}$ & 0 & 5 & 3 & 1 & 0 & 0 & 5 & 4 & 0 & 0 \\
\hline$\%$ & 0.0 & 56.0 & 33.0 & 11.0 & 0.0 & 0.0 & 56.0 & 44.0 & 0.0 & 0.0 \\
\hline \multicolumn{11}{|l|}{ High } \\
\hline $\mathrm{n}$ & 0 & 1 & 12 & 2 & 0 & 0 & 0 & 15 & 0 & 0 \\
\hline$\%$ & 0.0 & 5.0 & 25.0 & 55.0 & 15.0 & 0.0 & 0.0 & 0.0 & 100.0 & 0.0 \\
\hline \multicolumn{11}{|l|}{ Hyper-endemic } \\
\hline $\mathrm{n}$ & 0 & 0 & 1 & 3 & 14 & 0 & 0 & 0 & 4 & 14 \\
\hline$\%$ & 0.0 & 0.0 & 6.0 & 17.0 & 78.0 & 0.0 & 0.0 & 0.0 & 22.0 & 78.0 \\
\hline
\end{tabular}

of leprosy cases. There is also a greater concentration of cases in the north of the county and in the Continental Region, which consists of 14 districts. Spatial analysis shows that this region has areas with greater disease severity but with differences in the distribution of leprosy cases among districts; a higher concentration was observed in the Jabour district.

Once the existence of spatial dependence between rates was detected, the study investigated the incidence of local and differentiated regimes of disease occurrence. To accomplish this, the local Moran index (LISA) was used, which provides correlation values for each of the units under study (Figures 3A, B and C).

Figure 3B highlights the cities with estimated incidence rates that were statistically correlated $(p<0.005)$ with the existing correlation in their neighbors, as calculated by LISA (local spatial analysis).

Values greater than $95 \%$ are identified by the dependence in relation to the rates observed in areas of bordering neighborhoods. Figure 3 shows the classification of these regions as high- and low-risk, with an average city as the parameter. Regarding Figure 3C, high-risk areas are observed in the north of the county, in the region that corresponds to the Continental Health Region and to the west of the Maruipe Health Region. In other regions, there is low risk for leprosy.

\section{DISCUSSION}

Ecological studies have been widely used in the area of health research ${ }^{15,16}$. In the case of leprosy, spatial analysis is an important tool that provides information about the spatial structure and dynamics of the disease, which is the first step in characterizing a health status.

The study confirmed the magnitude of disease in the City of Vitória, demonstrating that it is an area with very high leprosy endemicity and showing that a considerable portion of the population is exposed to the disease.

The Empirical Bayesian method enabled the construction of maps with fixed coefficients. The Local Ebest method considers district detection according to the average of its neighborhood, and the Global Ebest method uses the city average for corrections. Using these methods, it was possible to observe areas with greater leprosy intensity and thus provide support for disease control strategies.

The findings in this study indicate high detection rates of leprosy, i.e., high risks for the disease, in the northern and western parts of the city, corresponding to the Continental and Maruipe Health Regions, respectively. Those regions that are at high risk for leprosy may be contributing to the appearance of new cases in areas with low detection rates.

The International Federation of Anti-Leprosy Association (ILEP) considers detection rates to be the best indicators of leprosy transmission, and one of the factors that influence its increase is the organization of health services. The increase in detection rates can be analyzed from two perspectives: the first reflects the active transmission of leprosy, which generates new cases in the area; the second reflects the possible existence of hidden prevalence ${ }^{17}$.

Health Region II, Maruipe, west of the city, has neighborhoods that had low detection rates compared to neighboring districts and generated higher coefficients of detection with the 


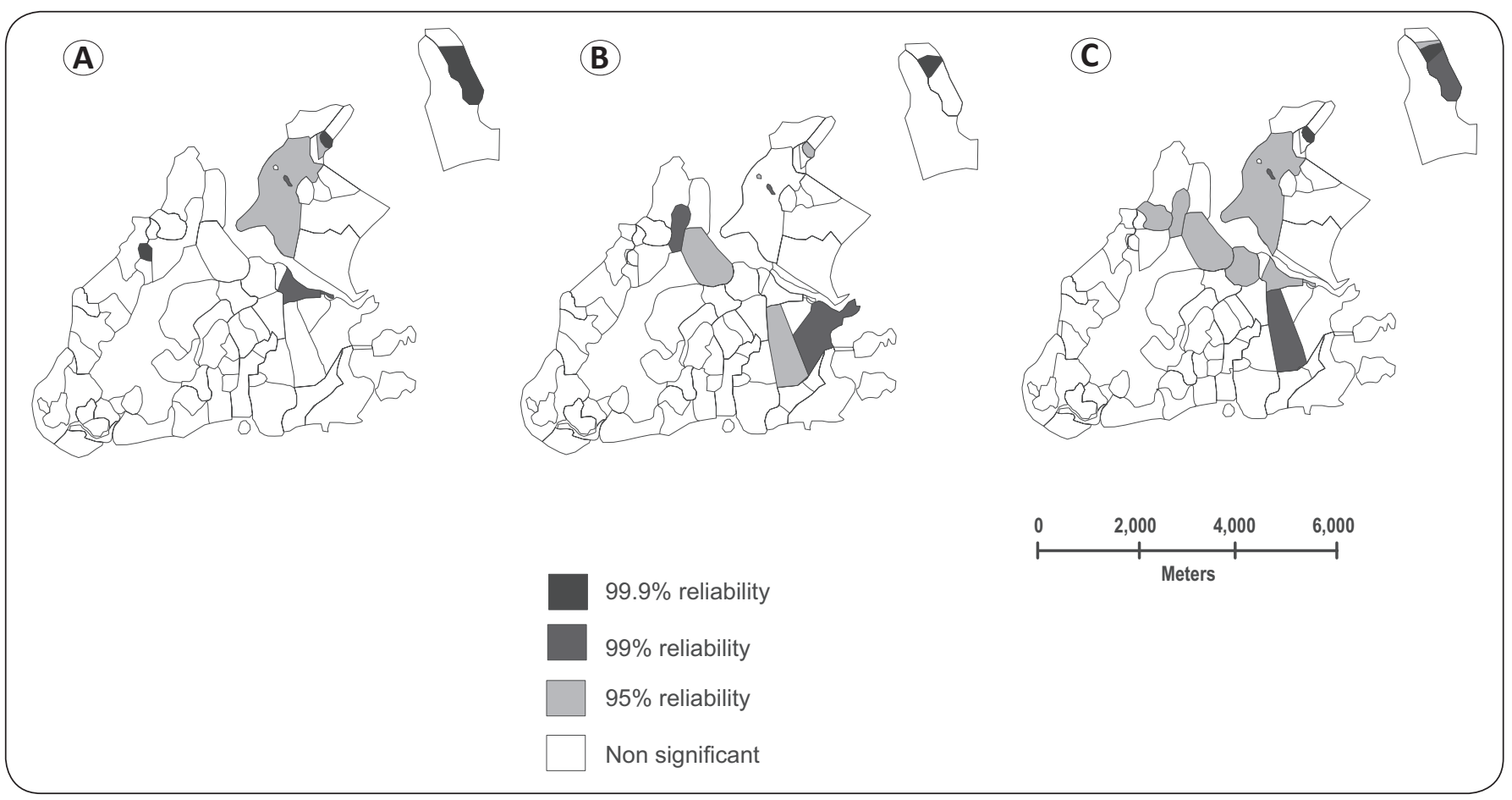

FIGURE 3 - Map of the Moran spatial correlation of the City of Vitória, State of Espírito Santo, Brazil, according to the detection of leprosy clusters, 2005 to 2009: A: raw coefficient; B: Adjusted coefficient using the Local Ebest method; C: adjusted coefficient using the Global Ebest method.

Bayesian method. The long and insidious clinical evolution of leprosy produces a delayed diagnosis, resulting in possible hidden prevalence, i.e., the accumulation of undetected cases. Therefore, the distribution of cases in region II with low detection rate is considered as worrisome as the neighborhoods with high detection rate.

The distribution of leprosy in areas of the county has been characterized as quite heterogeneous, as was demonstrated in other regions in Brazil ${ }^{5,18-20}$. Imbiriba et al. ${ }^{21}$ evaluated the epidemiology of leprosy and living conditions in Manaus State of Amazonas between 1998 and 2004 using the spatial distribution by census tract and identified sectors with an average detection rate that ranged from 0.66 to 24.60 cases per 10,000 inhabitants, thus revealing an inequality and clustering of cases characterized by the spatial organization of leprosy.

The dynamics of the disease in Vitoria resemble the worldwide pattern, showing high rates in poorer regions ${ }^{6,22}$. This finding is agrees with that of Bakker et al. ${ }^{23}$ who evaluated the risk factors for the development of leprosy in Indonesia and, in a study of a population-based cohort, demonstrated an important association between poverty and vulnerability to leprosy.

The work of Madeira ${ }^{24}$ attempted to identify urban areas/ regions at the greatest risk for transmission of leprosy in Vitória using the method of spatial analysis for points of occurrence, noting that the areas of highest endemicity were located in areas with low socioeconomic conditions. A study by Wood became a geographical reference for leprosy cases registered between 2003 and 2005 and used territories to present a distribution of cases with higher concentrations in the region of Sao Pedro, the Northwest Region and the North
Region, along with the Continental Region, as observed in this study.

Through spatial analysis, it was possible to identify areas at greatest risk for the transmission of leprosy. An area with a high disease incidence was the Continental area, located north of the Bay of Vitória, State of Espírito Santo, Brazil, particularly the Jabour neighborhood. This hyperendemic district has its origin in the early 70s; at the time, it was characterized as an immigrant neighborhood and was a neighborhood in which the City of Vitória deposited garbage. Only later did this neighborhood receive government investments for improving the social and urban infrastructure. Another distinctive area was the region of São Pedro, located in the northwest part of the city. This neighborhood was an area of recent immigration in the late $70 \mathrm{~s}$ and a place where families lived on stilts over the city landfill, demonstrating the poverty in the region ${ }^{24,25}$.

These migratory spaces suggest the possibility that sick people or their contacts have moved to the area, which can be a current source of infection in these areas due to the long incubation period of the disease. The findings of the study indicate the need to recognize the leprosy infection route to meet the challenges and implement measures in areas with high transmission rates.

The spatial distribution method used in the study enables the visualization of the processes of late urbanization in areas with the highest detection rates. It is also worth investigating the geographical relationships and the precarious living conditions of those sites that can generate consolidated foci of leprosy in regions with similar characteristics.

This study used a spatial distribution methodology to characterize the distribution of leprosy cases in Vitória; through 
smoothing, the methodology enabled a better understanding of spatial effects due to neighborhood influence, as shown by thematic map locations. Leprosy was heterogeneously distributed with respect to endemicity in the districts in the City of Vitória, State of Espírito Santo, Brazil.

The study used spatial analysis, thereby enabling the evaluation of areas showing high potential for leprosy transmission. The study also highlighted areas that should be priorities for municipal control programs to the north, northwest and west of the city.

Despite the limitations of ecologic-type studies ${ }^{26}$, in this study, the construction of maps identified changes that need to be implemented in the health system and can guide public policies to control this disease.

\section{CONFLICT OF INTEREST}

The authors declare that there is no conflict of interest.

\section{FINANCIAL SUPPORT}

This study was financially supported by MCT/CNPq/CTHealth/MS/SCTIE DECIT number 034/2008. Additional studies to assist in interventions for the control of leprosy in the cluster municipalities No.4 (ES, BA and MG).

\section{REFERENCES}

1. Vieira CSCA, Soares MT, Ribeiro CTSX, Silva LFG. Avaliação e controle de contatos faltosos de doentes com hanseníase. Rev Bras Enfer 2008; 61:682-688.

2. Bulletin of the World Health Organization (WHO). Number 36. Weekly Epidemiol Record 2011; 86:389-400.

3. Lobo JR, Barreto JCC, Alves LL, Crispim LC, Barreto LA, Duncan LR, et al. Perfil epidemiológico dos pacientes diagnosticados com hanseníase através de exame de contato no município de Campos dos Goytacazes, RJ. Rev Bras Clin Med 2011; 9:283-287.

4. Secretaria do Estado de Saúde do Espírito Santo (Sesa). Relatório avaliação anual da hanseníase 2009. Vitória: Sesa; 2010.

5. Sampaio PB, Rossi TL, Cerutti Junior C, Zandonade E. Análise Espacial dos casos novos de hanseníase nos municípios do Estado do Espírito Santo, entre 2004 e 2009. Rev Soc Bras Med Trop 2012; 45:380-384.

6. Ministério da Saúde. Secretaria de Vigilância em Saúde. Programa Nacional de Controle da Hanseníase. Hanseníase no Brasil. Dados e Indicadores Selecionados. Brasília: Ministério da Saúde; 2009.

7. Opromolla PA, Dalben I, Cardim M. Análise da distribuição espacial da hanseníase no Estado de São Paulo, 1991-2002. Rev Bras Epidemiol 2009; 8:356-364.
8. Joshua V, Gupte MD, Bhagavandas M. A Bayesian approach to study the space time variation of leprosy in endemic area of Tamil Nadu, South India. Int J Health Geographics 2008; 7:40.

9. Fundação Instituto Brasileiro de Geografia e Estatística (IBGE). Censo Demográfico 2009 - Agregado por setores censitários dos resultados do universo. Espírito Santo: IBGE; 2009.

10. Ministério da Saúde. Saúde Brasil 2009: Plano Municipal de Saúde 20102013. Resolução CMSV n. 359/2009. Vitória: Ministério da Saúde; 2009.

11. Ministério da Saúde. Saúde Brasil 2005: uma análise da situação de saúde no Brasil. Secretaria de Vigilância em Saúde, Departamento de Análise de Situação em Saúde. $2^{\mathrm{a}}$ Ed. Brasília: Ministério da Saúde; 2006.

12. Bailey TC, Gatrell AC. Interactive Spatial Data Analysis. Essex: Longman; 1995.

13. Anselin L. Local indicators of spatial Asssociation - LISA. Geogr Anal 1995; 27:93-115.

14. Ministério da Saúde. Brasil. Portaria no 3.125, de 7 de outubro de 2010. Aprova as Diretrizes para Vigilância, Atenção e Controle da hanseníase. Diário Oficial da Republica Federativa do Brasil. Brasília: Ministério da Saúde; 2010.

15. Duarte-Cunha M, Souza-Santos R, Matos HJ, Oliveira MLW. Aspectos epidemiológicos da hanseníase: uma abordagem espacial. Cad Saude Publica 2012; 28:1143-1155.

16. Cury MRC, PaschoalVA, Nardi SMT, Chierotti AP, Rodrigues Júnior AL, Chiaravalloti-Neto F. Spatial analysis of leprosy incidence and associated socioeconomic factors. Rev Saude Publica 2012; 46:110-118.

17. International Leaders in Education Program. The interpretation of epidemiological indicators in leprosy [Internet]. Technical Bulletin; 2011. [Cited 2011 December 01]. Available from: www.ilep.org.uk/ fileadmin/uplAoads/Documents/Technical_Bulletins/tb11eng.pdf.

18. Moreira MV, Waldman EA, Martins CL. Hanseníase no Estado do Espírito Santo, Brasil: uma endemia em ascensão?. Cad Saude Publica 2008; 24:1619-1630.

19. Villa TCS, Cunha TN, Santos CB. Distribuição espacial de doenças endêmicas no município de Ribeirão Preto (SP). Ciência e Saude Coletiva 2011; 16 (suppl I):1289-1294.

20. Amaral EP, Lana FCF. Análise espacial da Hanseníase na microrregião de Almenara, MG, Brasil. Rev Bras Enferm 2008; 61:S701-S707.

21. Imbiriba ENB, Silva Neto AL, Souza WV, Pedrosa V, Cunha MG, Garnelo L. Desigualdade Social, crescimento urbano e hanseníase em Manaus: abordagem espacial. Rev Saude Publica 2009; 43:656665.

22. Declercq E. Leprosy statistics 2009: some thoughts. Lepr Rev 2011; 82:87-89.

23. Bakker MI, Hatta M, Kwenang A, Van Mosseveld P, Faber WR, Klatser $\mathrm{PR}$, et al. Fatores de risco para o desenvolvimento de hanseníase - um estudo de coorte de base populacional na Indonésia. Lepr Rev 2006; 77:170.

24. Madeira ES. Os espaços de transmissão da hanseníase: domicílio, trabalho e relações de vizinhança. [Masters Dissertation].[Vitória]: Universidade Federal do Espírito Santo; 2006. 80p.

25. Prefeitura Municipal de Vitória. Histórico dos Bairros [Internet]; Vitória; 2006. [Cited 2011 November 29]. Available from: www.vitoria.es.gov.br/. 